Article

\title{
Senior Living Lab: An Ecological Approach to Foster Social Innovation in an Ageing Society
}

\author{
Leonardo Angelini ${ }^{1, *}$, Stefano Carrino ${ }^{1}$, Omar Abou Khaled ${ }^{1}$, Susie Riva-Mossman ${ }^{2}$ and \\ Elena Mugellini ${ }^{1}$ \\ 1 HumanTech Institute, University of Applied Sciences and Arts Western Switzerland, \\ Fribourg 1705, Switzerland; stefano.carrino@hes-so.ch (S.C.); omar.aboukhaled@hes-so.ch (O.A.K.); \\ elena.mugellini@hes-so.ch (E.M.) \\ 2 School of Nursing Sciences La Source, University of Applied Sciences Western Switzerland, \\ Lausanne 1004, Switzerland; su.riva@bluewin.ch \\ * Correspondence: leonardo.angelini@hes-so.ch; Tel.: +41-26-429-6745 \\ Academic Editor: Dino Giuli \\ Received: 16 April 2016; Accepted: 29 September 2016; Published: 21 October 2016
}

\begin{abstract}
The Senior Living Lab (SLL) is a transdisciplinary research platform created by four Universities that aims at promoting ageing well at home through the co-creation of innovative products, services and practices with older adults. While most living labs for ageing well are focused on Information and Communication Technologies (ICTs), this social laboratory adopts a transdisciplinary approach, bringing together designers, economists, engineers and healthcare professionals to develop multiple forms of social innovation using participatory methods. The SLL is based on an ecological approach, connecting professionals and users in a cooperative network and involving all of the stakeholders concerned with ageing well, such as existing associations, business entities and policy-makers. Three main themes for the co-design of products and services were identified at the beginning of the SLL conception, each sustained by a major business partner: healthy nutrition to cope with frailty, improved autonomous mobility to foster independence and social communication to prevent isolation. This article shows the innovative transdisciplinary approach of the SLL and discusses the particular challenges that emerged during the first year of its creation, investigating the role of ICTs when designing products and services for older adults.
\end{abstract}

Keywords: living labs; older adults; ICTs

\section{Introduction}

We live in an ageing society where the increasing older population depends on the shrinking working-age population. The EUROPOP2013 study estimates that in the EU the demographic old-age dependency ratio (people aged 65 or above relative to those aged 15-64) will increase from $27.8 \%$ in 2013 to $50.1 \%$ in 2060 . Therefore, the EU would move from having four working-age people for every person aged over 65 years to only two working-age people [1]. This will have an important economic impact on the healthcare and pension systems. In this context, it is crucial to promote initiatives for ageing well, supporting prevention and healthy lifestyles. The EU has supported several campaigns to promote ageing well, in particular through information and communication technology research, during the 7th Framework Programme and the Horizon 2020 (H2020) program, but also with dedicated programs, such as the Active and Assisted Living (AAL) Programme.

Making successful innovation for older adults hides several challenges that have to be addressed from the onset of the research project. For at least two decades, it has been advocated that individual behavior change is not sufficient in order to ensure an effective improvement of older adults' health [2]. An ecological action, i.e., a change also in the environment of the individual is often needed to support 
the promotion of healthy lifestyles and ensure their effectiveness [2]. This implies a change not only in infrastructure, but also to the existing supporting communities, policy-makers, healthcare professionals and business actors. This approach obtained good results for promoting older adults' health in France and Quebec [3]. In this context, the older adults as individuals still have an important role, since their needs should be well understood and they should be implicated, contributing throughout whole design processes of new products, services and practices. The Senior Living Lab [4,5] aims at promoting healthy ageing at home and strives to innovate for and with older adults through transdisciplinary research, creating products and services that can not only meet the functional requirements for which they have been developed, but that are also appealing, easy to use and affordable.

Exploiting an ecological approach, the Senior Living Lab (SLL) conducts community-based participatory research in the French-speaking part of Switzerland (Romandy) with a transdisciplinary team. The core of the Senior Living Lab is constituted by four academic partners with different areas of experience: business, design, engineering and nursing within the University of Applied Sciences and Arts Western Switzerland. Working together, these four domains allow the academic platform to tackle the challenges of co-creating with older adults, adhering to an ecological approach. Moreover, this academic core is reinforced by companies, associations and institutions willing to innovate in-tandem with older adults.

In this article, we aim to provide an overview of the key methodologies that are important for discussing the transdisciplinary approach and the role of technologies in a living lab for older adults, which is our main contribution. In light of this purpose, this article has the two-fold goal of: (1) presenting the transdisciplinary methodologies needed to design a living lab for older adults (highlighting the activities and interventions carried out during the first year of life of the laboratory) and the impact that they have in the functioning of the living lab; (2) discussing the role of ICTs when co-creating with older adults. Indeed, while on the one hand, the ICTs have the potential of improving the quality of life of older adults, on the other hand, older adults are often concerned by the potential negative impacts of ICTs on their lives. In this context, we propose a different solution: while most living labs for older adults conduct research and make innovation specifically in the domain of ICTs, the Senior Living Lab puts technology in the background, focusing more on general product and service innovation, using technology as an invisible support.

In the next sections, we describe the research context with respect to existing living labs, the goals of the Senior Living Lab and the participatory methodology used to co-create products, services and practices. The insights obtained during the first year open a discussion about the challenges of innovating when following an ecological approach. We think that our experiences could help other living labs or institutions that would like to co-create products and services with older adults.

\section{Background}

\subsection{Living Labs}

The living lab is a concept introduced by professor William Mitchell at the Massachusetts Institute of Technology (MIT) [6]. In its first meaning, the focus was on the observation of the living patterns of people inhabiting a smart house for several days. The basic idea that still remains in all of the current instantiations of the living lab concept is to include the users in a value-creation process.

According to Pallot et al. [6] "Living Labs are standing at the crossroads of different society trends like citizens engaged into a more participative approach, businesses and local authorities as well as user communities are gathering within public-private-people partnership initiatives. They are also at the crossroads of different paradigms and technological streams such as Future Internet, Open Innovation, User co-Creation, User Content Creation and Social Interaction (Web2.0), Mass Collaboration (i.e., Wikipedia), and Cloud Computing where the Internet is the cloud, also named "the disappearing IT infrastructure"."

Nowadays, the living lab concept is broader, and multiple definitions exist. This has brought forward the creation of different entities that coexist under the same large umbrella concept of living 
lab. In Europe, in order to coordinate the work, provide best practices and to disseminate the results achieved in the different living labs, an international federation of benchmarked living labs has been birthed: The European Network of Living Labs (ENoLL) [7].

According to the definition of the ENoLL [8] "Living Labs are defined as user-centred, open innovation ecosystems based on a systematic user co-creation approach integrating research and innovation processes in real life communities and settings. In practice, Living Labs place the citizen at the centre of innovation, and have thus shown the ability to better mould the opportunities offered by new ICT concepts and solutions to the specific needs and aspirations of local contexts, cultures, and creativity potentials."

Schuurman et al. (2013) [9] highlight the necessity of a clear conceptualization of what a living lab is. The authors assess that this is still a task in progress, but propose a four-fold categorization founded on living labs based on a literature review that empirically validated 64 ICT living labs from ENoLL. The four general living lab types that they propose are: (1) American living labs; (2) testbed-like living labs; (3) living labs focused on intense user co-creation; and (4) living labs mainly as facilitators for multi-stakeholder collaboration and knowledge sharing. According to this categorization, the Senior Living Lab has a closer relation with the third typology of living labs, in which the main goal is the co-creation of new services and products and the collection of information on the usage context with ethnographic approaches. According to Schuurman et al., "These Living Labs can focus on the early development phases of needs analysis and (iterative) design, where, based on an identified problem, a solution is developed in close interaction with end-users.".

We prefer this categorization to the one proposed by Leminen et al. [10] for different reasons. This last categorization proposes to differentiate living labs based on which actor drives their activities: utilizer-driven, enabler-driven, provider-driven and user-driven living labs. We believe that this latter categorization poorly fits our conception of the Senior Living Lab in which all of the actors play an important role. Certainly, the final users are at the center of the laboratory (thus, the Senior Living Lab is closer to user-driven living labs) but a consistent effort has been required to balance and take into account the impact of all of the different stakeholders.

In the co-creation process of the Senior Living Lab, we have considered the previous definitions focusing in particular on the necessity of adopting an ecological approach around the final users, i.e., the older adults. As we will explain in the next sections, this means that, differently from most of the existing living labs, the SLL does not follow a technology-centric approach, but focuses on the older adults' needs and their ecosystem.

An additional element that is often considered crucial for a living lab is to put the laboratory at the center of a Public-Private-People Partnership (4P). The foundation behind these new environments is to open academic and business boundaries to harvest creative ideas and exploitable facilities that can be found among the different project stakeholders.

Few scientific papers can be found about living labs. Schuurman et al. [11] underlined this lack, thanks to a systematic review of existing research articles in this domain. Furthermore, they concluded that many articles were merely descriptive, without proposing theoretical advances or empirical results. The lack of empirical results in scientific papers can be explained by the role that private companies may play inside a living lab. Companies can request scientific partners to limit or omit the publication of most of the results in order to avoid leaking confidential information.

Shuurman et al. [9] also highlighted that most living labs were still in an exploratory phase, which implicitly raises the problem of living labs' sustainability. Mastelic et al. [12] suggested to use the business model canvas [13] to investigate the sustainability of living labs that are members of ENoLL. Their research showed that most living labs are in an exploration phase and that only a few have been able to move to the exploitation phase. Baccarne et al. [14] suggest an open business model innovation approach, involving stakeholders in the definition of the business model itself. Conversely, Doppio and Pianesi [15] propose a service paradigm in which a host offers services to a guest inside the living lab. 
In this paper, discussing the first year of life of the Senior Living Lab, we will focus on the theoretical innovations that we propose for our specific goal of designing products and services for older adults and on the controversial role of ICT for this target population.

\subsection{Living Labs and Older Adults}

Considering the specific target of the Senior Living Lab, we have identified several European living labs dealing with challenges linked to healthy ageing and older adults. For the analysis that we present in this section, we focus on living labs that are members of ENoLL, using the data publicly available about their activities at the end of 2015. From the complete list of ENoLL living labs available on the ENoLL website [7], we individuated the living labs working with older adults. The selection and classification of existing living labs was performed separately by two SLL members; complete agreement was achieved after discussion. The living labs were classified according to the following criteria analyzing the information on the ENoLL website and the respective living lab websites:

- Work on ICT (25)

$\bigcirc \quad$ Work only on ICT (10)

○ Home automation/domotic (10)

- Smart objects (4)

○ Telemedicine/tele-assistance (11)

Robots (3)

- Have multiple target population and not only older adults (12)

- Have a specific goal (17)

Autonomy (11)

Isolation (2)

Specific illness (8)

Counselling (2)

- Work with older adults' caregivers and doctors (9)

- Have an ecological approach (8)

The number of living labs respecting each criterion are highlighted in parentheses. It is worth noting that some living labs may comply with more than one criterion (even in the same category).

Our research highlighted 28 living labs spread across Europe working in this specific field or strictly related domains (Austria 1, Belgium 6, England 2, France 7, Germany 1, Ireland 1, Italy 2, Spain 5, Sweden 2, Switzerland and Hungary 1). Some of the living labs are strictly linked together and work in complementary domains (e.g., Care living labs in Belgium) or belong to a national/regional platform linking different labs acting in different domains (e.g., InnovaPuglia, which links 79 local living labs in the Puglia region in Italy). The considered living labs are listed in Appendix A.

It is worth noting that in more than the $43 \%$ of the cases, older adults are not the only target population of the reviewed living labs. In fact, often, the proposed interventions focus also on people in the environment of the older adults (e.g., caregivers, families, doctors and nurses) or people with psycho-physical conditions that are similar to those of older adults (e.g., hospitalized people, impaired people or people with particular diseases or illness).

As mentioned in the previous paragraphs, a universally-accepted definition of living lab does not exist and, therefore, the adopted approaches are quite different and the modalities of users' involvement in the co-creation process are very heterogeneous. However, one result is particularly evident: living labs are very often linked to ICTs (in several living lab definitions, ICT is indeed a requirement [16]). In fact, most of the projects born inside European living labs aim at creating innovation thanks to novel technologies. In detail, about $90 \%$ of the living labs analyzed have projects dealing with the co-creation of ICTs, whereas the other $10 \%$ deal more with the creation of services impacting socio-economical 
aspects or creating innovation in medical technologies. Projects span different areas of ICT, but among the different services and solutions proposed, the development of home automation solutions (35\%) and telemedicine or tele-assistance services (39\%) clearly stand out. In addition, most of the living labs deal with specific challenges linked to ageing, such as autonomy (39\%).

In $21 \%$ of the living labs, actions are undertaken to have an impact on the older adults' ecosystem via the training of caregivers, nurses or doctors in several domains (and particularly, in the use of new technologies) or organizing informative events and workshops.

Even if all of the living labs aim at creating public-private-people partnerships, only $28 \%$ explicitly aim to enlarge this collaboration beyond the partners of the living lab, and just a few are explicitly focusing on an ecological approach.

Although the most fundamental notion behind the concept of the living lab is the integration of the users in the co-creation process, a unique definition on how the user should be involved is missing. This, again, has led to the creation of different methodologies under the umbrella concept of the living lab. For example, two typical approaches can be considered at the extremes of the living lab concept. On one side of the spectrum, we have cases in which a product already exists in a quasi-complete form and the users are only involved in the testing and fine-tuning of the product. On the other side of the spectrum, we have users actively participating from the beginning in the co-creation process, highlighting actual needs. The first approach leads to services and products based on business needs. Thanks to the support of the companies, these products and services can easily enter the market, but risk to not attend to the real needs of the target population. The second approach, on the other hand, allows the generative process to focus on concrete needs of the target population; however, such projects risk not reaching the market since the ideas proposed can be beyond the core business of the companies involved in the living lab. It is worth noting that those approaches and the risks evoked are not uncommon in living labs and can undermine their long-term sustainability. The understanding of the functioning of the living lab by all of the partners is therefore mandatory in order to prevent possible conflicts.

Differently from most of the existing living labs dealing with older adults, the Senior Living Lab aims at designing new products, services and practices and leaves ICTs in the background, focusing its activities on the co-design of innovation via an ecological approach. In this process, technologies play a supportive role, more or less influential according to the specific context.

\subsection{Older Adults and Technology}

Older adults' relationship with technology is heterogeneous, depending on age, gender, type of technology, availability of technology facilitators, price and many other factors [17,18]. Chen and Chan [17] reviewed several studies on technological acceptance in different contexts. Although many older adults have a positive attitude towards technology, they use it less than younger adults, and they show less interest in adopting new technologies. The explanation of the scarce older adults' adoption of technology can be found in Technology Adoption Models (TAM) [19] and in the more recent models Unified Theory of Acceptance of Use of Technology (UTAUT) [20] and UTAUT2 [18]. In particular, in the latest study, Venkatesh et al. [18] demonstrated that facilitating conditions (e.g., relatives supporting the learning of novel technologies) and price value are particularly important in relation to the behavioral intention to use technology pertaining to older women and that the habit has an effect on older men in later stages of experience.

Among the most relevant factors that influence the technology acceptance and adoption, Chen and Chan [17] cite the perceived usefulness, the perceived ease of use and personal characteristics, such as biophysical characteristics, sensation and perception, mobility, cognition, psychosocial characteristics and social relationships. In the context of assistive technology, Bright and Coventry [21] suggest that in order to obtain desirable devices, it is important to pay particular attention to the aesthetic design of the product, avoiding stigmatization and resemblance with medical devices, as well as to align the usefulness and usability with the desirability of the product. 
Concerning the usability and accessibility of technology, in 2006, Pattison and Stedmon [22] analyzed the typical problems that older adults can have while interacting with mobile phones, suggesting design guidelines that can take into account the possible physical and cognitive impairments of older adults. Current touchscreen smartphones have improved the usability for older adults over traditional phones, but they still have much room for improvement, since older adults are often neglected as target users [23]. Touch interfaces have facilitated the access to digital information for older adults, thanks to improved learnability over traditional Window, Icon, Menu, Pointer (WIMP) interfaces [24], increasing the diffusion of Internet and other digital services among older adults. A recent report in Switzerland attested that the diffusion of Internet usage among older adults increased by $47 \%$ from $2009-2014$, but still $44 \%$ of over 65 users lack Internet access. The report also shows a split attitude towards technology, equally distributed among technology enthusiasts, who are interested in new technologies and that have a good experience with them and those that are more reluctant [25].

The introduction of technology in older adults' lives can open several opportunities, increasing their quality of life and independence. According to the European Community, this could also have a huge economic impact on the whole society. Nevertheless, McLean [26] underlines that most initiatives that promote ICT for older adults do not really come from the actual expectations and needs of older adults. Most technology for older adults is designed and developed by engineers, as a potential solution to common problems, but without including many older adults in the design and development of this solution. Indeed, promoting e-inclusion and offering easy-to-use digital services and products often ignore the opinion of a small, but still considerable, part of older adults that do not accept technology in their lives. According to McLean [26], alternative solutions that do not make use of technology should be provided for these people.

A living lab that seeks innovation through a transdisciplinary and participatory approach could be able to address these questions and deal with the ethical issues that are particularly relevant in this field. Involving older adults from the very beginning of the product, service development and practice definition, starting from actual expressed and unexpressed needs and recurring to technology only when it is perceived as effectively useful, is the strategy adopted by the Senior Living Lab.

\section{Goals of the SLL}

\subsection{Ageing Well at Home}

As the rest of Europe, Switzerland is a country where the median age of the population is increasing and, therefore, ageing well and staying healthy is a social and also economic priority to improve the quality of life of older adults and, at the same time, to reduce the expenditure for long-term healthcare. The Senior Living Lab role in this context is to support ageing well at home for older adults (defined as 65+ people), but also including people who are approaching the retirement age (60+ people). The main population target of the project are older adults that are still functionally independent or that are entering a new phase of life in which they are confronting a form of frailty. Very different cultures and languages characterize Switzerland. This project focuses its activities on the French-speaking part of Switzerland. To achieve ageing well at home, the Senior Living Lab concentrates its efforts on three more specific axes, described in the next subsection.

\subsection{Co-Creation of Products, Services and Technologies (Three Axes)}

Three axes of investigation have been individuated through preliminary semi-structured interviews before the beginning of the project: nutrition, social relationships and mobility. For each research axis, the Senior Living Lab strives to co-create with older adults, generating new products, services and practices that existing business entities will introduce into the market.

The first axis, nutrition, aims at investigating the challenges that older adults are facing, from acquiring products and using services available in a supermarket, to promoting healthy nutrition. 
For this axis, the Senior Living Lab cooperated with a well-known supermarket chain, which is interested in offering personalized services and products in order to create a better shopping experience for older adults.

The second axis investigated by the Senior Living Lab is facilitating communication with older adults to prevent social isolation and related risks. Indeed, several studies demonstrated that individuals with stronger social connections have generally better cognitive functions, better health [27] and, as a result, longer life [28]. For this axis, the Senior Living Lab is collaborating with a leading ICT provider in Switzerland.

Finally, a key factor for preventing older adults' dependency is ensuring autonomous displacements away from home. Mobility is also a crucial factor ensuring a network of social relationships and increasing the opportunity for social contacts [29]. For this reason, the Senior Living Lab is also collaborating with a local transportation company that wants to improve its offer of services for older adults.

\subsection{Community Making and Link-Building}

In order to reach older adults for co-creating products, services and practices, it is mandatory to build a community that is akin to support the Senior Living Lab. Looking for older adults "in the wild" could be time consuming and cost-demanding; therefore, creating a network through existing associations and institutions is fundamental.

Involving strategic actors at academic, associative and political levels in order to define and design the Senior Living Lab activities is crucial, ensuring an ecological approach that can bring tangible results into the older adults' everyday life. In this sense, it is crucial that the Living Lab is perceived in his role of mediator and facilitator for existing entities, instead of being perceived as a competitor, vying for resources within the network.

\section{Methodology of the SLL}

In [5], we have presented the methodologies used to co-construct social innovation inside the Senior Living Lab, referring to a social constructionist approach. The reader can refer to the article for a complete overview describing the Senior Living Lab methodologies. In this article, we aim to provide a framework depicting the key methodologies that have been implemented in the field, discussing the specificities mentioned in this article, i.e., the transdisciplinary approach, as well as the role of technologies in a living lab from the perspective of older adults that participated in-tandem with university researchers.

\subsection{Ecological Approach}

Since the ecological approach is crucial in the functioning of the Senior Living Lab, we discuss how we implemented this approach in this sub-section.

Ecological models have gained relevance in studies in many disciplines and fields (e.g., public health, sociology, biology, education, psychology, etc.) [30]. Several studies, such as [3,31], demonstrate the positive impact that can be obtained creating programs that act on multiple determinants and targets. In particular, inside the scientific community for several years now, there is a broad consensus that programs based on ecological approaches are more effective than traditional ones [2,30,32].

Nevertheless, existing programs for health promotion for older adults tend to adopt a traditional approach targeting individual determinants, instead of more innovative approaches that consider the target population and the related ecosystem [33]. This is mainly because programs based on ecological approaches implement multiple goals, require very different know-how and are therefore typically harder to design and realize in practice. In fact, ecological approaches need to consider multiple determinants of health and, therefore, necessitate a transdisciplinary team of researchers and partners. Ecological approaches should be able to act on: (a) the individuals; (b) their immediate local context; and (c) the larger context where they live, such as their community or social context. 
A living lab design methodology naturally facilitates the implementation of an ecological approach. In particular:

- Living labs deal with the target users in their environment. In this way, it is possible to acquire knowledge that was not accessible in classical laboratory settings.

- A living lab is a public-private-people partnership. Therefore, it has by design the capability to provide multi-level actions and interventions around the target population.

Therefore, the Senior Living Lab distinguishes itself from the other living labs working in the same area for the involvement in its activities, and from the beginning, of all of the stakeholders around the problematic of healthy ageing. The involvement of the different stakeholders is strictly dependent on the political, societal and economic conditions of the Swiss society. For this reason, during the first year of operation, the Senior Living Lab conducted a survey of existing older adult stakeholders in the French-speaking part of Switzerland. The purpose of the survey was to identify potential partners, gain access to the older population and investigate project opportunities where the Senior Living Lab could offer its transdisciplinary competencies.

Each SLL founding partner, in particular the School of Nursing Sciences La Source, which is already in contact with several older adults' stakeholders, collected a list of potential entities that could become partners within the Senior Living Lab. During a Senior Living Lab meeting with all of the founding partners, lists of potential partners were collected. Entities belonging to the same categories have been regrouped, and a mind-map has been created.

The different entities identified as possible partners within the Senior Living Lab have been labelled in eight different categories:

- Associations: There are several local and national associations that offer a varied support for older adults: some of them offer specific support related to older age diseases (e.g., Alzheimer and Parkinson); other associations support local leisure and cultural activities; others defend older adults' rights or gather volunteers for older age support.

- Medical-social entities: Several public and private entities offer specific medical and social support to older adults. Among them, Pro Senectute (https://www.prosenectute.ch) and the Swiss Red Cross (http:/ / www.ifrc.org) offer several services and social activities for older adults. Several nursing retirement homes and associations for home help and care exist. Their interests are represented at regional (cantonal) level by the respective associations.

- Medical entities: This category embraces the proper Swiss medical entities, such as local hospitals and University hospitals.

- Business entities: Every business entity that offers products and services for the population could be a potential Senior Living Lab partner.

- Urbanism: The entities that design and regulate the Swiss population's everyday environment have an important role, ensuring the environmental accessibility to older adults, encouraging older adults' mobility and preventing older adults' isolation, accidents and falls.

- Political entities: Political institutions have a critical role in ensuring older adults' well-being. Besides formal Swiss political institutions, such as cantons, communes and cities, there are other national-level institutions that defend older adults' rights from a political point of view.

- Foundations: There are few Swiss private and public foundations that support ageing-related projects.

- Academic entities: Besides the four academic institutions that founded the Senior Living Lab, many other Swiss Universities conduct research dealing with ageing well. Collaborating with the existing research centers is important because it allows the SLL to take advantage of existing knowledge, creating synergies in specific domains of application.

These eight categories include the major actors, allowing the Senior Lab to act on the aforementioned axes (immediate and larger context) typical of an ecological approach. 
The relations with each of these categories have to be carefully considered in the development of a living lab. In fact, complex relations can arise slowing down the activities of a new laboratory. For instance, taking into account the "associations" category, when creating a new laboratory, it is very important to clarify as soon as possible the living lab's role in relation to the existing entities in order to avoid unjustified rivalries.

Even if this research was conducted in Switzerland, this taxonomy can be easily extended and applied to categorize living labs stakeholders in Europe and abroad.

\subsection{Community-Based Participatory Research in the SLL}

Participatory approaches are commonly adopted by most living labs and are particularly important to meet the needs of older adults and avoid misconceptions. User-centered design techniques are adopted broadly in the fields of service design and human-computer interaction. Indeed, involving the user from the beginning of each project is mandatory to ensure that the designed product or service will be effectively used or purchased by the older adults [34].

Community-Based Participatory Research (CBPR) focuses on ecological perspectives, as described in the previous section, to act on the different determinants of health. CBPR should consider the individuals in the community, their local context, as well as the larger context in which the community acts, such as their societal context [35].

The Senior Living Lab has used different user-centered techniques to investigate older adults' needs using a bottom-up strategy. Starting from the lower, individual level, in these first years of life, the Senior Living Lab has focused its activities on ethnological studies (more details about these user-centered techniques are presented in Section 5):

- Focus groups are a typical method to debate about open topics, such as nutrition, mobility and interpersonal communication, but also to investigate the perception of existing products, services and practices in relation to older adults.

- Another powerful tool to collect insights is the World Café [36], which aims at investigating specific questions through a participatory approach.

- Shadowing techniques [37] are a form of ethnographic study that allow discovering the latent needs of older adults, by following them during their daily activities and listing observations.

Organizations and entities working at the local and national levels have been contacted in order to establish partnerships to design ecological interventions and actions.

The insights collected through the different ethnographic studies are then incorporated into the next phase of creative thinking, generating innovation in the specific field addressed by the project in order to collectively imagine a response to older adults' most pertinent needs.

\subsection{Products, Services and Practices Design: A Transdisciplinary Approach}

The previous section described how the Senior Living Lab collects the user requirements through a participatory approach. In the design thinking methodology [38], this is often called the "empathize" phase, which follows the "define" phase in which all of the observations are collected, refined and discussed to understand the user requirements. The next phase, "ideate" involves a generative process for collecting as many ideas as possible that could solve the problem or that could rethink completely the way a certain service or product is used. The next step, "prototype" is materializing one or more of these ideas into a mock-up or prototype that the user could test to provide feedback. Indeed, "test" is the last phase of the design thinking innovation process, which iterates the different phases until an acceptable working solution is found.

Having the end-user at disposal during the whole process for assessing the ideas and testing the different prototypes is crucial in obtaining usable and appealing products and services. Meanwhile, it is also important to highlight that the whole process is conducted by a transdisciplinary team, able to conceive of multi-facetted ideas thanks to the diverse backgrounds of the participants 
within the creative process. In a transdisciplinary team, each member can contribute with their own knowledge and expertise, but collective efforts determine the most suitable ideas or approaches. In fact, this co-creative scenario, in which older adults, companies and institutions participate and exchange know-how, facilities and needs, is particularly apt for the design of interventions acting on multiple determinants. The concept of a transdisciplinary team is slightly different from an interdisciplinary team, which is typically intended to have members working on their own solutions separately and, during the final steps, merging together the different responses towards a final solution [39].

The presence of healthcare professionals and engineers within the team ensure that functional requirements are met, while design professionals ensure that the product and services are usable, innovative and appealing for the user. At the same time, business professionals ensure that the product and service are marketable, generating value for the involved business entities. Combining these multiple perspectives with the collaboration of the final users allows a more balanced impact of technologies, i.e., making them closer and more acceptable to the user, while at the same time, bringing forth a product or service that is valuable in terms of the market.

\subsection{Business-Oriented Sustainability}

The Senior Living Lab was born in 2014 as an academic research project founded by a Swiss private foundation. One of the objectives of the project is transforming the Senior Living Lab into an autonomous entity that is able to operate sustainably over a long period of time. In order to achieve this goal, the Senior Living Lab should offer a catalogue of unique services that business entities and other institutions would pay to hire.

The Senior Living Lab's purpose it to establish a sustainable functioning process to continue innovation for older adults after the end of the initial research project. While in the first phase the initial funding will support the development of a product or service for each of the three axes described in Section 3.2, after the end of the funded period, the Senior Living Lab should be able to operate autonomously. As in other living labs [15], the business model should be based on a catalogue of services that could be offered to strategic partners, which can be found among the list of older adults' stakeholders, presented in Section 4.1.

A typical service offered by existing living labs is the access to the end-users for testing and co-designing services and products. Following this idea, since business entities often struggle to find end-users to co-design and test products, the Senior Living Lab could act as a mediator or facilitator between the older adults, the business entities and the other stakeholders that would like to involve this particular category of users in their product or service definition.

Besides this typical service, the Senior Living Lab could offer unique services that other associations are not able to propose, benefiting from the internal competences of the transdisciplinary team and the strong links with the associative, institutional and political worlds. Thanks to the background of the academic partners, the Senior Living Lab could provide unique insights and ideas exploiting participatory design techniques. Indeed, the individual competencies of each founding university provide knowledgeability for designing products or services that align functional and health-related requirements with usability and aesthetics [19], ensuring at the same time the economic viability of the proposed product or service.

In order to analyze the sustainability of the Senior Living Lab and clearly identify a strategy for the next years, we have applied the Business Model Canvas (BMC) [13] to project the functioning of the laboratory in a long-term view, as suggested by the work of Mastelic et al. [12]. The solutions considered are strictly linked to the functioning of the University of Applied Sciences in Western Switzerland, and a deep focus on this analysis goes beyond the scope of this article. However, it is worth highlighting that, as a result of the BMC analysis, a living lab working as a facilitator among the different stakeholders was the more interesting approach, while the University partners should have the role of financing the bare minimum, guaranteeing the functioning of the laboratory solely in the case that private or third party funds are not available. This is particularly interesting since it 
comports a pivot in the role of the Senior Living Lab. According to the taxonomy of Schuurman [9], the role of the living lab would move from a (3) living lab focused on intense user co-creation to (4) a living lab acting mainly as a facilitator for multi-stakeholder collaboration and knowledge sharing. This shift makes perfect sense if we consider that the first years of life a living lab strives to understand the concrete needs of the users, develop methodologies and, finally, create the relations with the different communities of stakeholders. In this scenario, the living lab is no longer incarnated just by the university's research entities, but becomes an autonomous entity in which the academic members will become (privileged) stakeholders of the laboratory.

\section{Senior Living Lab Activities}

This section highlights the activities performed by the Senior Living Lab during its first year of life. In particular, we focus on the description of the types of participatory activities that we have conducted and the role played by the users in those activities. During the first year, our primary focus was on nutrition and mobility, two of the three main axes. The work in relation to the communication axis has been planned during a two-year period.

The activities carried out were the following:

- Two world cafés (one per axis)

- Two focus groups (one per axis)

- Six ethnographic studies: shadowing (three per the axis nutrition; three per the axis mobility)

- Three workshops (one per axis)

These activities are summarized in Figure 1. Whilst older adults participated in all of the activities, industrial partners were involved in only specific events. In addition to the previous activities, a documentary film was made with the participation of the senior women's group in Valais. A round table discussion was organized at the Avant-Premiere film presentation, highlighting hopeful aging themes expressed within the documentary. This cultural axis brought together community stakeholders in a dialogical space devoted to envisioning an ecological approach to citizen-centered approaches to healthy aging.

Since these are ongoing activities, an analysis of the results cannot be published yet (results are to be considered confidential with the involved economical stakeholder), and therefore, this section focuses on the methodologies used during the different activities.

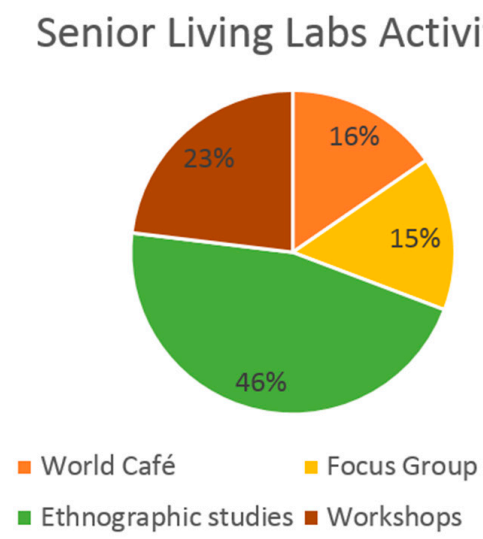

Figure 1. Activities of the SLL (Senior Living Lab) during the first year.

\subsection{Case Study 1: Improving the Supermarket Experience}

The first case study was conducted in collaboration with a well-known Swiss supermarket chain. Within the axis of nutrition, the aim of the project is improving the senior-friendliness of their supermarkets, in particular in the cantons of Valais and Vaud. 


\subsubsection{Activities}

In order to better understand the unexpressed needs of the older adults concerning the shopping experience and the theme of nutrition, different activities have been carried out, which include 3 ethnographic studies using the shadowing technique, 1 focus group and 1 world café. The three ethnographic studies consisted of following two women living alone and a married couple during a shopping experience, not only inside the supermarket, but also before and after the shopping experience, at home and during the displacement from home to the supermarket. The ethnographic studies have been conducted in different cities and allowed the Senior Living Lab to understand the older adults' shopping and nutrition habits.

Moreover, ethnographic observations and a focus group including supermarket chain employees were carried out in Valais, with a "senior" group constituted from the regional Senior Living Lab participants, this needs assessment phase provided the methodological foundation for data collection, storying the shopping experience, a key factor within the topic of nutrition.

The second participatory activity was a world café that involved 26 participants. Four questions were discussed at each table: the first question investigated the most valuable elements identified in relation to the older adults' healthy aging, imagining innovative ways to obtain them; the second one investigated the important things that they would like to find in the supermarket chain; the third one investigated the interpersonal exchanges that developed in the supermarket chain; the fourth question explored novel ideas to foster ageing well together.

\subsection{Case Study 2. Mobility with Public Transportation}

The second case study was conducted in collaboration with a Swiss provider of public transportation. Similar to the previous case study, the aim of the different activities was to analyze and improve the senior-friendliness of public transportation. For this analysis, our geographical focus was the Canton of Vaud.

\subsubsection{Activities}

As with the previous topic, different activities have been carried out, including 3 ethnographic studies using the shadowing technique, 1 focus group and 1 World Café.

The ethnographic studies consisted of following three different older adults with different physical capabilities and limitations travelling with public transportation in the Lausanne area. The study was not limited to investigating the activities inside the means of transport, but the whole travel experience: buying tickets, waiting for the transportation means, getting on, travelling, etc.

The focus group was structured to analyze different issues linked to mobility, beginning with a more generic perspective and ending with specific transportation service issues for older adults living in the Lausanne area. The focus group was structured in four parts in order to investigate four different elements. The first part of the focus group aimed at investigating challenges and issues related to mobility from a general perspective. The second part investigated challenges and issues related to public transportation. The third part confronted the older adults with the specific solutions provided nowadays by the current services and that are specifically designed for older adults. The fourth part was dedicated to analyzing specific communication strategies and products designed by the transportation service provider.

\section{Discussion: Role of ICT in the SLL and Participatory Design Practices}

The activities conducted during the first year allowed the researchers within the Senior Living Lab, in tandem with the "senior researchers", to collect many specific insights concerning the two mobility and nutrition axes. However, we consider these insights out of the scope of this paper. Instead, in this section, we will focus on and discuss the insights obtained about the SLL methodology. In particular, we want to highlight the difficult role of ICTs when some older adults involved in the co-creation process are generally unsympathetic towards those more technical solutions. 


\subsection{Technology Fear versus Innovation}

Information and communication technology have received increasing attention from the research community to support ageing well. The H2020 and the AAL programs particularly encourage the application of ICT as a support for older adults' everyday life. While there are clear benefits of using technologies for this purpose, older adults are often afraid of technology. Even if this statement is controversial (some studies stated that older adults have positive attitudes toward technologies [40]), our experience confirmed this attitude during the different focus groups that we organized. In particular, the reason for this fear is not only related to the difficulty to learn a new interface, but it is often related to the fear of losing social contacts with other people because of the technology. Unfortunately, this fear is often well justified, because many digital services tend to replace the human operator, in order to cut costs and speed up the operation. While this is acceptable for younger people, older adults, especially those living alone, often regret that in our increasingly digitalized society, they are losing many opportunities for social exchanges with other people.

As a solution toward this attitude, the Senior Living Lab and other living labs for ageing well should not be presented to older adults as a technology mediator. In addition, products and services that would be co-designed with older adults should not necessarily involve technology. Nevertheless, technology plays a relevant role in innovation and, if correctly designed, has the potential of having a huge impact on the quality of life of elders. This is a real contradiction, and the fear of new technologies can block the development and the creation of innovations potentially helpful to older adults. This is particularly relevant in participatory design approaches in which older adults are involved from the beginning of the conceptual design of a solution and can therefore ostracize the adoption of novel technologies.

As the results of the first year's activities (world cafés, focus groups, ethnographic studies and workshops involving more than 100 participants), we have learned that:

(1) Invisible technologies (technologies that are transparent to the user's eyes as in the Mark Weiser definition [41]) can reduce the fear of novel technologies. This kind of solution is well accepted by older adults in particular if they address a specific need. Invisible technologies are an important field of study in the human-computer interaction field. For instance, in one of the focus groups organized by the Senior Living Lab, older adults had shared consensus in disliking solutions based on the generic idea of creating objects enriched by displays or touch screens. However, they appreciated the idea of having "augmented" physical objects, if they are already confident with the utilization of the object. For instance, the participants liked the idea of having a technologically-enhanced magnifying glass to use in a supermarket context to retrieve additional information about a product by just using the glass on the product. In this example, older adults do not have to learn how to use a new tool or navigate in a touch screen menu, they already know how to use it. They just have the possibility to use it with new objects to obtain different information. This is a clear example of invisible technology.

(2) The use of technology is highly stratified by age, gender, marital status and educational background. This is confirmed also from other studies, such as [39]. Therefore, designers of interfaces have to carefully consider these aspects and adapt their solutions to the target population for which they are designing a technological solution. In other terms, in most of the cases, "older adults" is not a good enough segmentation for the design of ICT-based solutions.

(3) The usefulness of a technology is not enough to make a product or service acceptable: it is crucial to avoid the older adults' stigmatization. Products or services that are explicitly presented as being designed for older adults are likely avoided by seniors, since it is considered equivalent to the admission of belonging to this group. In addition, a clear category of "older adults" does not exist, since age is not always the pertinent criteria allowing researchers to segment the aforesaid population. Instead, physical and mental disabilities together with the cultural baggage of the person play a major role, impacting user needs. 


\subsection{Addressing Older Adult's Needs versus Stigmatization}

Designing products and services with older adults specifically thought through with their lens and perception of needs leads to products and services that are often labelled as such and that have only older adults as target customers. In this case, older adults tend often to consider these products and services as stigmatizing, especially if used in front of their relatives and friends. Products and services designed with older adults to address their specific needs should be designed and sold as a product or service for all and not as specifically designed for older adults. This is sometimes counterintuitive for both the business entities and for the Senior Living Lab. Indeed, the business entities would like to improve their products and services for older adults and want to advertise those efforts. Similarly, the Senior Living Lab is interested in labelling the designed products and services with its logo as an advertisement of its work and also as a guarantee for the older adults of a "senior friendly" product or service. At the time of writing this article, it remains to be known if a Senior Living Lab "senior friendly" label would be accepted by the older adults or if it would be perceived as stigmatizing.

Concerning this point, the lesson learned from the first year of co-design with older adults is that designers should be able to present to the older adults a concept in the real scenario of utilization as soon as possible in order to ensure the acceptability of the product.

\subsection{Usefulness versus Usability}

Technology can provide many functionalities for older adults, addressing different needs with different features. However, adding several functionalities to the same product or service can make the interface more complex, thus more difficult to understand and use. This is a typical issue of general-purpose commercial devices, which often cannot satisfy older adults' needs because of usability issues. Conversely, devices designed specifically for older adults are often oversimplified and suffer from stigmatization. From our previous experiences, we noticed that tangible interaction could help hiding the complexity of technology behind a physical interface that exploits the previous knowledge of the user through meaningful interaction metaphors. In particular, the seamless integration of technology into everyday objects could help older adults accept it.

\subsection{Participatory Approach versus Older Adults' Expectations}

Beyond technologies, a key challenge during the creation of the Senior Living Lab has been its wish to be founded via a participatory approach. The goal of this approach was to ensure the functioning of the laboratory around the specific needs of the local target population having the older adults participating within the co-creation process of the laboratory. During the kick-off event and during a first world café, we asked older adults what they would expect from the Senior Living Lab, with a particular focus on the three action axes described in Section 3.2. The results of this participatory kick-off that sought to collaboratively define the Senior Living Lab's main actions were themselves controversial. Indeed, many attendees at the kick-off expected a concrete and clear action plan from the Senior Living Lab, aiming as soon as possible to obtain tangible results. In fact, at this time, the older adults did not understand their role and how they could belong to the laboratory even though an introductory presentation tried to explain their important role and the contributions that they could make as senior participants.

The lesson learned from this experience is that, in the first period of life of a living lab, it is important to balance the participatory approach with more concrete actions. These actions should be established and discussed internally by the Senior Living Lab's constituting members, since the initial participatory process could be perceived as a lack of internal organization that could slow-up the results of the project from the older adults' perspective. Participatory governance must be jointly practiced and learned. Most participants are not familiar with grass-root processes that engender collaborative results. 


\subsection{Participatory Approach versus Business-Oriented Projects}

One of the hardest challenges of the Senior Living Lab was combining the participatory approach with the business-oriented purpose of the Senior Living Lab. Although the development of business-oriented services and products together with business actors is fundamental to bring the innovation to the end-user, the collaboration with those actors was sometimes perceived negatively by the older adults. In other terms, while older adults are keen to collaborate with academic institutions, the same cannot be said for business entities. In a few occasions, older adults expressed their concern of being exploited by the companies and that the Senior Living Lab was financed by business entities to collect information about them and, in the end, just to sell more products and services.

With the goal of mitigating this effect, we proposed an advisory board composed of older adults that would be involved in the decision-making process of the laboratory. Older adults deeply appreciated this idea since they felt more "in control" and not just passive actors in the laboratory. The lesson learned is that it is very important to illustrate correctly to the older adults their active role in a living lab, i.e., that they are part of the laboratory and not just testers. At the same time, it is also important to underline the benefits that they and their peers will receive in the long term via their participation (e.g., products that respond to their concrete needs). In fact, it should be clear for the participants that they are actively contributing to the development of a product that will improve their quality of life. This clarification is important for all of the stakeholders.

\subsection{Ethics and Related Concerns}

Working with a vulnerable population can give rise to ethical issues. This is particularly true in connection with medical programs needing to acquire medical-level data. Thanks to the different figures involved in the laboratory, and in particularly to health specialists, these issues are handled taking advantage of their experience and, in addition, an ethical commission will evaluate and approve all of the interventions that deal with medical and personal information.

It is therefore important to highlight that if no personal or medical data are acquired and stored and as the interventions do not impact on the medical dimensions of senior lifestyles, the ethical commission is not required to be involved.

The initial participants were invited to the Senior Living Lab kick-off meeting, contacting associations and institutions that daily collaborate with older adults and also via the personal network of the Senior Living Lab participants. For logistical and organizational reasons, we limited the number of participants to about 30 people (including researchers, partners from the industry and older adults). During this meeting, older adults interested in participating in the work of the laboratory provided contact information.

The organization of the following activities has been based on these very positive first results, and this has engendered the solidification of a contact network facilitating the organization of activities.

Finally, to meet older adults' privacy concerns, all of the sensible data acquired during the interventions are anonymized and hosted in private university servers.

\subsection{Participatory Approach versus Concrete Needs}

Understanding and taking into account the end-users' needs is mandatory in order to apply an open innovation approach and to design products and services that respond to such needs. However, tackling the question of older adults' individual needs could be a challenging task on many occasions, because older adults' needs are heterogeneous and can vary according to the personal health status, the different physical and cognitive disabilities, as well as the personal social and cultural backgrounds. Older adults often expose very particular needs that could not be addressed in each project, especially if a business-oriented goal is set to ensure the operationalization of the innovation action. While ensuring accessibility to products and services to minorities is an ethical and often legal duty for the researchers 
and the public business operators, taking into account the minor needs of all of the users is practically impossible and economically not sustainable in most of the cases.

In this context, during the first phases of co-creation, it is crucial to individuate the older adults' shared needs, without ignoring obstacles that could hinder the access to products and services to people with particular cognitive or physical impairments. Sometimes, accessibility problems could be solved with slight design changes, which can also improve the overall usability of the product or service for other groups of people. When accessibility problems could not be solved without increasing the complexity and the cost of the product or service, it is probably preferable to provide alternative solutions and services that can better meet the needs of the minority. In this case, a human mediator could be the most economic and appreciated solution. Shared value is a central vision that ultimately federates the interests of elders, stakeholders and communities. The configuration of a mediating platform is a process emerging from participatory governance, giving value to citizen-centered solutions to healthy aging.

\section{Conclusions and Perspectives}

In this paper, we have presented the Senior Living Lab, a living lab created in Switzerland and aiming at promoting ageing well at home pathways through the co-creation with older adults of innovative products, services and practices. The Senior Living Lab is based on participatory design and on an ecological approach.

During the first year of life of the Senior Living Lab, many insights have been gathered. This paper presents the insights relative to the SLL methodology and the role of the ICT in this context.

Compared to the existing living labs within the ENoLL network, the Senior Living Lab proposes a different approach with regard to novel technologies. In particular, we have seen that older adults are generally insecure when dealing with ICTs. The causes can be different and vary with the older adult's age, culture and health conditions, as well as with the application context. A major issue is the association of technologies with a diminution of human and social contacts. From our perspective, the primary objective of a living lab is not to design novel ICT solutions, but to provide ecological solutions to specific issues. In this scenario, technologies are fundamental, but can be made invisible or acceptable to the final users if carefully designed involving the user in the process from the very beginning. In fact, we have observed that when applying participatory design methodologies, older adults will rarely propose solutions involving novel technologies. On the other hand, they are open to discuss new technology propositions and include them if they feel that the technology will not negatively affect their lifestyle (e.g., reduction of social contacts, stigmatization, etc.).

Living labs have to maintain a precarious balance between academics, companies, associations, political entities and the final users, while working together in an ecological approach. During the first year of life, the Senior Living Lab has experimented with the necessity of have a transdisciplinary team in order to face the very different challenges that this rich heterogeneity can potentially generate. Transdisciplinarity is therefore the key to enable a living lab to design and realize actual ecological interventions.

In the next year, the academic partners in collaboration with the companies will concretize the results of the first phases of co-design. Obviously, this second phase will also include the users in the implementation and evaluation of the tasks. Meanwhile, the SLL partners are working to define a business plan allowing the living laboratory to be sustainable and keep living in a long-term scenario.

Acknowledgments: This research project was funded by Gebert Rüf Stiftung (GRS/067/14) and the University of Applied Sciences Western Switzerland. We thank our partners Henk Verloo, Delphine Roulet Schwab, Nataly Viens Python, Luc Bergeron and Nathalie Nyffeler for their participation in this research project. We also thank University of Applied Sciences Western Switzerland School of Nursing La Source, Lausanne, Switzerland, the University of Applied Sciences Western Switzerland, Ecole Cantonale d'Art de Lausanne (ECAL), Lausanne, Switzerland, the University of Applied Sciences Western Switzerland School of Business and Engineering, Yverdon, Switzerland, and the University of Applied Sciences Western Switzerland School of Engineering and Architecture, Fribourg, Switzerland, for their contribution. 
Author Contributions: All of the authors participated in conceiving of and designing the Senior Living Lab methodologies and experiments. Leonardo Angelini and Stefano Carrino wrote the paper, while Omar Abou Khaled, Susie Riva-Mossman, and Elena Mugellini revised it and contributed to its improvement.

Conflicts of Interest: The authors declare no conflict of interest.

\section{Abbreviations}

The following abbreviations are used in this manuscript:

$\begin{array}{ll}\text { AAL } & \text { Active and Assisted Living } \\ \text { CBPR } & \text { Community-Based Participatory Research } \\ \text { ENoLL } & \text { European Network of Living Labs } \\ \text { H2020 } & \text { Horizon 2020 } \\ \text { ICT } & \text { Information and Communication Technology } \\ \text { SLL } & \text { Senior Living Lab }\end{array}$

\section{Appendix A}

Following is the list of living labs considered in Section 2.3, Older Adults and Technology (when available, a link to the living lab description is provided).

- AAL Living Lab Schwechat: http://www.ceit.at/ceit-raltec/aal-living-lab-schwechat

- Living Lab ActivAgeing (LL2A): www.activageing.fr

- Autonom' lab: http://www.autonom-lab.com/

- Living and Care Lab (LiCaLab): www.LiCaLab.com

- CASALA Living Lab: www.casala.ie

- Cyber Care Clinique Living Lab (CCCL)

- e-Care Lab: Innovative Care Living Lab In Rhône-Alpes: http://www.i-carecluster.org/ presentation-living-lab/

- eHealthMadrid Living Lab

- eHealth Living Lab à Grenade

- $\quad$ FZI Living Lab: http://aal.fzi.de

- LUSAGE Living Lab: http://www.lusage.org/

- InnovAGE: http://www.innovage.be

- Innovate Dementia Transnational Living Lab

- Smart House Living Lab: www.lst.tfo.upm.es

- Seniorlab

- Lab4Living: www.Lab4Living.org.uk

- Silver Normandie HUB: http://miriade-innovation.fr/silver-normandie/normandiehub/

- Softex (Swedish Open Facility for Technology in Elderly Care)

- Stockholm Living Lab

- $\quad$ THAT: Tele Health Aging Territory

- TELESAL

- VisAge Living Lab

- $\quad$ AIPA: Ageing in Place Aalst

- ONLINE neighborhoods: http://openlivinglabs.eu/livinglab/online-neighbourhoods

- Careville Limburg: Moving Care: http://www.zorgproeftuinen.be/en

- Active Caring Neighborhood: http://www.zorgproeftuinen.be/en

- Apulian Living Lab on "Healthy, Active \& Assisted Living" (INNOVAALab): http:/ / www.openlivinglabs.eu/livinglab/apulian-ict-living-lab

- Living Lab Social in real environments: Ageing Lab 


\section{References}

1. European Commission. The 2015 Ageing Report: Underlying Assumptions and Projection Methodologies; European Union: Brussels, Belgium, 2014; pp. 1725-3217.

2. Stokols, D. Establishing and maintaining healthy environments: Toward a social ecology of health promotion. Am. Psychol. 1992, 47, 6-22. [CrossRef] [PubMed]

3. Richard, L.; Barthélémy, L.; Tremblay, M.; Pin, S.; Gauvin, L. Interventions de prévention et promotion de la santé pour les aînés: Modèle écologique. In Guide D'aide à L'action Francoquébécois. Saint-Denis: Inpes, Coll. Santé en Action; INPES: Saint Denis, France, 2013. (In French)

4. Angelini, L.; Carrino, F.; Carrino, S.; Caon, M.; Khaled, O.A.; Baumgartner, J.; Sonderegger, A.; Lalanne, D.; Mugellini, E. Gesturing on the steering wheel: A user-elicited taxonomy. In Proceedings of the 6th International Conference on Automotive User Interfaces and Interactive Vehicular Applications-AutomotiveUI'14, Seattle, WA, USA, 17-19 September 2014; pp. 1-8.

5. Riva-Mossman, S.; Kampel, T.; Cohen, C.; Verloo, H. The senior living lab: An example of nursing leadership. Clin. Interv. Aging 2016, 11, 255-263. [PubMed]

6. Pallot, M.; Trousse, B.; Senach, B.; Scapin, D. Living Lab Research Landscape: From User Centred Design and User Experience towards User Cocreation. In First European Summer School "Living Labs"; HAL: Paris, France, 2010.

7. Ashbrook, D.; Lyons, K.; Starner, T. An investigation into round touchscreen wristwatch interaction. In Proceedings of the 10th International Conference on Human Computer Interaction with Mobile Devices and Services-MobileHCI'08, Amsterdam, The Netherlands, 2-5 September 2008; pp. 311-314.

8. Atia, A.; Takahashi, S.; Tanaka, J. Smart gesture sticker: Smart hand gestures profiles for daily objects interaction. In Proceedings of the 2010 IEEE/ACIS 9th International Conference on Computer and Information Science, Yamagata, Japan, 18-20 August 2010; pp. 482-487.

9. Schuurman, D.; Mahr, D.; De Marez, L.; Ballon, P. A fourfold typology of Living Labs: An empirical investigation amongst the enoll community. In Proceedings of the 2013 International Conference on Engineering, Technology and Innovation (ICE) \& IEEE International Technology Management Conferenceon, The Hague, The Netherlands, 24-26 June 2013; pp. 1-11.

10. Leminen, S.; Westerlund, M.; Nyström, A.G. Living labs as open-innovation networks. Technol. Innov. Manag. Rev. 2012, 2, 6-11.

11. Schuurman, D.; De Marez, L.; Ballon, P. Living labs: A systematic literature review. In Open Living Lab Days; European Network of Living Labs: Istanbul, Turkey, 2015.

12. Mastelic, J.; Sahakian, M.; Bonazzi, R. How to keep a living lab alive? info 2015, 17, 12-25. [CrossRef]

13. Osterwalder, A.; Pigneur, Y. Business Model Generation: A Handbookfor Visionaries, Game Changers, and Challengers; John Wiley \& Sons: Hoboken, NJ, USA, 2013.

14. Baccarne, B.; Schuurman, D.; Seys, C. Living labs as a navigation system for innovative business models in the music industry. In Proceedings of the ISPIM Conference on International Society for Professional Innovation Management, Helsinki, Finland, 16-19 June 2013; p. 1.

15. Doppio, N.; Pianesi, F. Co-creating an open working model for experience \& living labs willing to provide services to external players. In Proceedings of the 4th EnoLL Summer School, Manchester, UK, 27-30 August 2013.

16. Eriksson, M.; Niitamo, V.P.; Kulkki, S. State-of-the-Art in Utilizing Living Labs Approach to User-Centric ICT Innovation-A European Approach; Center for Distance-spanning Technology, Lulea University of Technology Sweden: Lulea, Sweden, 2005.

17. Chen, K.; Chan, A. A review of technology acceptance by older adults. Gerontechnology 2011, 10, 1-12. [CrossRef]

18. Venkatesh, V.; Thong, J.Y.; Xu, X. Consumer acceptance and use of information technology: Extending the unified theory of acceptance and use of technology. MIS Q. 2012, 36, 157-178.

19. Davis, F.D.; Bagozzi, R.P.; Warshaw, P.R. User acceptance of computer technology: A comparison of two theoretical models. Manag. Sci. 1989, 35, 982-1003. [CrossRef]

20. Venkatesh, V.; Morris, M.G.; Davis, G.B.; Davis, F.D. User acceptance of information technology: Toward a unified view. MIS Q. 2003, 425-478. 
21. Bright, A.K.; Coventry, L. Assistive technology for older adults: Psychological and socio-emotional design requirements. In Proceedings of the 6th International Conference on Pervasive Technologies Related to Assistive Environments, Island of Rhodes, Greece, 29-31 May 2013; p. 9.

22. Pattison, M.; Stedmon, A.W. Inclusive design and human factors: Designing mobile phones for older users. PsychNology J. 2006, 4, 267-284.

23. Page, T. Touchscreen mobile devices and older adults: A usability study. Int. J. Hum. Factors Ergon. 2014, 3, 65-85. [CrossRef]

24. Holzinger, A. Finger instead of mouse: Touch screens as a means of enhancing universal access. In Universal Access Theoretical Perspectives, Practice, and Experience; Springer: Berlin, Germany, 2002; pp. 387-397.

25. Seifert, A.; Schelling, H.R. Digital Seniors; Pro Senectute: Zurich, Switzerland, 2015; p. 102.

26. McLean, A. Ethical frontiers of ICT and older users: Cultural, pragmatic and ethical issues. Ethics Inf. Technol. 2011, 13, 313-326. [CrossRef]

27. Dimatteo, M.R.; Giordani, P.J.; Lepper, H.S.; Croghan, T.W. Patient adherence and medical treatment outcomes: A meta-analysis. Med. Care 2002, 40, 794-811. [CrossRef] [PubMed]

28. Berkman, L.F.; Syme, S.L. Social networks, host resistance, and mortality: A nine-year follow-up study of alameda county residents. Am. J. Epidemiol. 1979, 109, 186-204. [PubMed]

29. Mollenkopf, H. Enhancing Mobility in Later Life: Personal Coping, Environmental Resources and Technical Support; the Out-of-Home Mobility of Older Adults in Urban and Rural Regions of Five European Countries; Ios Press: Amsterdam, The Netherlands, 2005; Volume 17.

30. Green, L.W.; Richard, L.; Potvin, L. Ecological foundations of health promotion. Am. J. Health Promot. 1996, 10, 270-281. [CrossRef] [PubMed]

31. Richard, L.; Gauvin, L.; Raine, K. Ecological models revisited: Their uses and evolution in health promotion over two decades. Annu. Rev. Public Health 2011, 32, 307-326. [CrossRef] [PubMed]

32. McLeroy, K.R.; Bibeau, D.; Steckler, A.; Glanz, K. An ecological perspective on health promotion programs. Health Educ. Behav. 1988, 15, 351-377. [CrossRef]

33. Richard, L.; Gauvin, L.; Gosselin, C.; Ducharme, F.; Sapinski, J.P.; Trudel, M. Integrating the ecological approach in health promotion for older adults: A survey of programs aimed at elder abuse prevention, falls prevention, and appropriate medication use. Int. J. Public Health 2008, 53, 46-56. [CrossRef] [PubMed]

34. Wilkinson, C.R.; De Angeli, A. Applying user centred and participatory design approaches to commercial product development. Des. Stud. 2014, 35, 614-631. [CrossRef]

35. Parker, E.A.; Robins, T.; Israel, B.; Brakefield-Caldwell, W.; Edgren, K.; Wilkins, D. Methods in Community-Based Participatory Research for Health; Jossey-Bass: San Francisco, CA, USA, 2005.

36. Brown, J. The World Café: Shaping Our Futures through Conversations that Matter (Large Print 16pt); ReadHowYouWant: Culver City, CA, USA, 2010.

37. Czarniawska-Joerges, B. Shadowing: And Other Techniques for Doing Fieldwork in Modern Societies; Copenhagen Business School Press DK: Copenaghen, Denmark, 2007.

38. Brown, T. Design thinking. Harv. Bus. Rev. 2008, 86, 84-92. [PubMed]

39. Max-Neef, M.A. Foundations of transdisciplinarity. Ecol. Econ. 2005, 53, 5-16. [CrossRef]

40. Mitzner, T.L.; Boron, J.B.; Fausset, C.B.; Adams, A.E.; Charness, N.; Czaja, S.J.; Dijkstra, K.; Fisk, A.D.; Rogers, W.A.; Sharit, J. Older adults talk technology: Technology usage and attitudes. Comput. Hum. Behav. 2010, 26, 1710-1721. [CrossRef] [PubMed]

41. Weiser, M. The computer for the 21st century. Sci. Am. 1991, 265, 94-104. [CrossRef]

(C) 2016 by the authors; licensee MDPI, Basel, Switzerland. This article is an open access article distributed under the terms and conditions of the Creative Commons Attribution (CC-BY) license (http://creativecommons.org/licenses/by/4.0/). 